\title{
TRABALHAR EM ESPAÇOS INSEGUROS: A FRONTEIRA MÉXICO-EUA A PARTIR DO OLHAR DAS TRABALHADORAS SEXUAIS
}

\author{
Susanne Hofmann ${ }^{1}$
}

\section{RESUMO}

O artigo enfatiza uma perspectiva da fronteira México-EUA como um local de atração e um recurso para mulheres de vários estados da República Mexicana. Trabalho extenuante e salários baixos pagos nas empresas transnacionais na fronteira tornam o trabalho sexual uma opção de trabalho preferível para algumas mulheres. $\mathrm{O}$ artigo destaca como a fronteira continua a ser uma barreira exclusiva para muitos cidadãos, apesar da prevalência simultânea de dinâmicas de mobilidade transnacional. Ele discute as distinções sociais que a fronteira produz, bem como as resistências que os indivíduos desenvolvem para distanciar-se do valor simbólico e material do cruzamento da fronteira. Do ponto de vista das experiências vividas pelas trabalhadoras sexuais, o artigo desenvolve uma crítica de abordagens analíticas que atribuem a violência e a insegurança na margem do Estado a instituições estatais distantes, e demonstra que a insegurança e a exposição à violência que as trabalhadoras sexuais enfrentam em Tijuana é, de fato, intrinsecamente ligado aos efeitos da governança de ambos os estados de fronteira, cruzando-se de forma negativa com modalidades específicas do comércio do sexo.

Palavras-chave: Fronteira México-EUA. Trabalho Sexual. Insegurança Espacial. Tijuana. Migração.

${ }^{1}$ Associate Fellow. School of Sociology and Social Policy. University of Leeds. Email: s.hofmann@leeds.ac.uk 


\begin{abstract}
The article emphasises a perspective of the US-Mexico border as a site of attraction and a resource for women from various states of the Mexican Republic. Strenuous work and poverty wages paid at transnational companies at the border make sex work a preferable work option for some women. The article highlights how the border continues to be an exclusive barrier for many citizens despite the simultaneous prevalence of dynamics of transnational mobility. It discusses the social distinctions that the border produces as well as the resistances that individuals develop to distance themselves from the symbolic and material value of border crossing. From the perspective of the lived experiences of sex workers the article develops a critique of analytical approaches that attribute violence and insecurity at state margins to distant state institutions. The article demonstrates that the insecurity and exposure to violence that sex workers face in Tijuana is indeed intrinsically connected to the effects of the governance of both border states, intersecting in negative ways with particular modalities of the sex trade.
\end{abstract}

Keywords: US-Mexico Border. Sex Work. Spatial Insecurity. Tijuana. Migration. 


\section{Introdução: Migrar para o norte...}

A migração para o norte de trabalhadoras do sexo $^{2}$ mexicanas faz parte de um movimento migratório mais amplo de mulheres jovens em busca de oportunidades de trabalho na fronteira EUA-México. Mulheres migram para o norte com o desejo de melhorar as suas perspectivas de vida. Aquelas que confluem para a fronteira são, muitas vezes, mulheres para as quais o modelo doméstico tradicional não deu certo. Sendo muitas delas mães solteiras e chefes de família, têm de encontrar suas próprias maneiras de mantê-las. Então, as mulheres migrantes deixam a segurança e a familiaridade de suas casas para trás e partem para um destino desconhecido e novo. Suas viagens exigem um senso de aventura e coragem, assim como a disposição de novos lugares e experiências. Como a maioria dos imigrantes, elas são pessoas com aspirações de sair de seus lugares de origem, não só no sentido geográfico, mas também em termos de status social.

Melissa Wright (2006), analisando os discursos de gerentes de fábricas na fronteira EUA-México, aponta que as mulheres mexicanas que têm migrado para o norte são retratadas por eles como pessoas sem aspirações, que só pensam em ter amantes e bebês. Nesse discurso, as mulheres migrantes transformam-se em resíduo humano das corporações transnacionais; elas podem ser utilizadas durante um pequeno número de anos e, em seguida, ser eliminadas e substituídas por outras trabalhadoras jovens. Nas narrativas dos gestores, as mulheres migrantes mexicanas que trabalham nas fábricas ao longo da fronteira aparecem com falta de motivação, vitalidade e autodeterminação.

À semelhança dessa essencialização cultural das mulheres mexicanas pelos gerentes, as profissionais do sexo muitas vezes são consideradas mulheres preguiçosas, desmotivadas para aprender ou para trabalhar duramente, e, portanto, fazem o que "naturalmente" ocorre a elas, vender sexo, uma profissão que, nessa lógica, não requereria nem competências nem ambições profissionais. Com este trabalho, quero

${ }^{2} \mathrm{Eu}$ estou usando a forma feminina "trabalhadoras do sexo" neste artigo, porque meu estudo se concentrou em apenas mulheres profissionais do sexo. Há trabalhadores sexuais masculinos e transgêneros em Tijuana que também trabalham na zona de prostituição com arranjos diferentes e com diferentes efeitos em sua segurança. Para um estudo sobre os trabalhadores do sexo transgêneros ver CASTILLO, RANGEL GÓMEZ e ROSAS (2006). 
desconstruir estas essencializações estigmatizantes de trabalhadoras sexuais que migram para a fronteira México-EUA. As trabalhadoras do sexo, bem como as operárias na fronteira, têm migrado com ambições e aspirações em mente. Suas viagens são muitas vezes parte de projetos pessoais destinados a melhorar as suas vidas.

\section{Chegar na fronteira}

Pretendo analisar o trabalho sexual no contexto das oportunidades de trabalho existentes para as mulheres na fronteira, onde o trabalho em maquiladoras $^{3}$ é uma das alternativas mais significativas. Com o acordo de livre comércio NAFTA, em 1994, e a facilitação do comércio entre Canadá, EUA e México, muitas empresas transnacionais mudaram-se para a zona fronteiriça EUA-México, oferecendo empregos para trabalhadores não qualificados, preferencialmente mulheres, não sindicalizadas. As preferências das corporações resultaram em uma enorme migração de mulheres dos estados mexicanos pobres do sul, como Oaxaca, Puebla e Guerrero, entre outros.

Muitas trabalhadoras sexuais com as quais falei fizeram referência ao trabalho nas maquilas, expressando sua preferência pelo trabalho sexual. ${ }^{4} \mathrm{O}$ trabalho nas maquilas é árduo, potencialmente ameaçador

\footnotetext{
${ }^{3}$ Uma maquiladora (também conhecido como maquila) é uma fábrica que importa e monta componentes com isenção de impostos para a exportação. $\mathrm{O}$ arranjo permite que os proprietários das fábricas tirem proveito de trabalho de baixo custo e de pagar impostos apenas para o "valor adicionado", isto é, para o valor do produto acabado menos o custo total dos componentes que tinham sido importados para produzi-lo. As Maquiladoras se originaram no México na década de 1960, com muitas das plantas localizadas nas cidades fronteiriças no norte do México. As maquiladoras se tornaram um meio de proporcionar emprego e ganhos significativos em divisas para a economia mexicana. As palavras maquiladora/maquila derivam da palavra espanhola "maquilar", o que significa processar (material) para uma taxa; maquila é a "taxa de processamento".

${ }^{4} \mathrm{O}$ trabalho de campo para este estudo foi realizado em dois períodos, totalizando 10 meses entre 2006 e 2008. A maioria das entrevistas com profissionais do sexo foi realizada no Departamento de Controle Sanitário, a clínica de saúde do governo localizada na zona de prostituição, mas algumas também em outros locais. Além disso, eu frequentava a zona de prostituição em diferentes momentos do dia, entrando em uma série de clubes de sexo, bares e cantinas, conversando com trabalhadoras do sexo, clientes, garçons, seguranças e gerentes. Eu também realizei entrevistas com profissionais de saúde, médicos, psicólogos e trabalhadores de ONGs e conversei com moradores da zona de prostituição sobre a vida no bairro.
} 
em relação à saúde (SALZINGER, 2003; WRIGHT, 2006) e de baixa remuneração. Em comparação, o trabalho sexual pode parecer a muitas mulheres uma ocupação saudável e menos árdua. Assim, calculando custo e benefício, algumas mulheres preferem o trabalho sexual, porque ele permite menos horas de trabalho e uma renda mais alta, além de horários mais flexíveis de trabalho, o que pode ser significativo para mulheres que têm responsabilidades de cuidado de crianças, por exemplo.

Nesse artigo, apresento como a zona de fronteira EUA-México tornouse um recurso em si mesmo, sendo alvo de mulheres com aspirações, que deixam suas casas a fim de fazer uso estratégico da zona fronteiriça cuja economia é dirigida a extrair dinheiro de seu vizinho rico e a fornecer serviços ajustados às necessidades e desejos dos cidadãos dos Estados Unidos. Muitas trabalhadoras sexuais na fronteira EUA-México são migrantes de classes socioeconômicas desfavorecidas, iniciando um processo de auto-realização, ${ }^{5}$ utilizando os seus corpos de formas estratégicas.

As mulheres com as quais eu falei haviam viajado para a fronteira norte do México de diferentes estados da República, tais como Baja California, Puebla, Jalisco, Durango, Sinaloa, Estado de México, Chihuahua e Chiapas. Muitas chegaram com a esperança de melhores condições de vida na fronteira ou no outro lado. No entanto, a falta de oportunidades de emprego, e o custo de vida elevado, em combinação com a necessidade de obter recursos financeiros para manter suas famílias, pressionaram as mulheres a buscar alternativas uma vez que elas tinham chegado. A trabalhadora sexual Elisa ${ }^{6}$ me disse que começou a trabalhar no comércio do sexo porque ela era pobre. Ela vem de uma cidade muito pobre, e os pais dela são agricultores que vivem em uma casa onde apenas as necessidades básicas são satisfeitas. Elisa até conseguiu entrar na universidade, mas logo

${ }^{5}$ Eu uso o termo auto-realização, a fim de destacar que, para muitas trabalhadoras do sexo com as quais conversei, vender sexo era um meio não só para asegurar sua sobrevivência, mas também para atingir sua auto-realização. Por exemplo, criar seu próprio estilo de vida através de escolhas particulares de consumo era parte de sua justificativa para se envolver no trabalho sexual. Os projetos de auto-realização das trabalhadoras sexuais geralmente aspiraram à criação de um estilo de vida particular junto com a mobilidade social. A utilização do termo auto-realização também pretende destacar a estratégia, a determinação e o foco intenso subjacente a perseguição do empoderamento através do trabalho sexual.

${ }^{6}$ Todos os nomes dos profissionais do sexo foram alterados pela autora. 
percebeu que não tinha suficientes recursos para continuar seus estudos e decidiu tentar a sorte no outro lado da fronteira.

Quando eu percebi que eu não tinha o dinheiro para estudar, eu disse a mim mesma: "Eu irei então", eu tinha a intenção de atravessar a fronteira. Bem, mas depois de chegar aqui você se envolve na situação sem querer, mesmo que não seja o seu plano. Bom, não foi minha intenção de vir aqui e fazer isso [vender sexo], mas passo a passo, você começa a trabalhar, pessoas convidam você, e então você vê que é dinheiro, um bom dinheiro, e então você fica (Elisa, 25 anos, de Colima).

Muitas narrações das mulheres sobre sua entrada na indústria do sexo em Tijuana apresentaram um elemento sedutor. Apesar de ter chegado com diferentes intenções, elas acabaram trabalhando na zona de prostituição. Para entender essa sedução, precisamos entender, em primeiro lugar, que as corporações transnacionais na zona fronteiriça ainda só pagam salários que não permitem que as trabalhadoras prosperem e vivam uma vida boa. Em segundo lugar, em locais noturnos de Tijuana fora da zona de prostituição, acontecem trocas sexuais-econômicas que permitem que as mulheres se familiarizem com a cobrança por atividades que geralmente são percebidas simplesmente como cortesias específicas de gênero ou entretenimento. As trabalhadoras do sexo na zona de prostituição cobram um dólar por dançar com um homem a música local, ${ }^{7}$ como ranchera ou salsa, e mulheres fora da zona de prostituição - em locais noturnos "normais" - começaram a cobrar também, para complementar seus baixos salários nas fábricas ou no setor de serviços. Isto parece ser apenas mais um passo para se envolver em outras atividades sexuaiseconômicas na zona de prostituição, o que permite uma ampla variedade de interações comerciais sexuais de intimidade, como taxidancing, stripping no palco, hostessing (trabalhar como anfitriã), table dance personalizado, massagem sexual e prostituição, e as mulheres determinam em quais atividades elas querem se envolver.

Muitas mulheres contaram que foram convidadas a trabalhar nos clubes. Na época do meu trabalho de campo (entre 2006 e 2008), os estabelecimentos de sexo comumente exibiam cartazes de recrutamento fora dos seus locais, para as mulheres notarem quando elas atravessassem a zona norte - a zona de prostituição de Tijuana -

\footnotetext{
${ }^{7} \mathrm{Na}$ literatura norte-americana esta prática é muitas vezes referida como taxi-dance.
} 
durante o dia. Estabelecimentos de sexo também anunciavam em ginásios locais e nas áreas turísticas de Tijuana. Até 2012, quando uma nova lei sancionou todos os tipos de anúncios sexuais, também foi possível encontrar anúncios de vagas em locais de sexo em alguns jornais locais. ${ }^{8}$ Muitas vezes os taxistas tinham atuado como intermediários que colocaram mulheres recém-chegadas em contato com os gestores de um determinado bar ou clube. A decisão de trabalhar em um dos 210 clubes noturnos de Tijuana (CASTILLO, RANGEL GÓMEZ e DELGADO, 1999, p. 403), ${ }^{9}$ em muitos casos, foi o resultado de uma mistura complexa de oportunidades, histórias pessoais e condições de vida da pessoa. Amaya é uma das mulheres que chegou em Tijuana com diferentes intenções e, em seguida, ficou trabalhando na indústria do sexo:

Eu só passei por aqui a fim de conhecer o lugar. Eu não tinha a intenção de ficar. Houve um problema, dois carros foram comprados em vez de uma van, como planejado, e acabamos sem dinheiro. Eu tinha uma criancinha. Em cima disso, eu não tenho meus papéis em ordem. É por isso que eu não poderia trabalhar em um lugar onde eu poderia ganhar um bom salário (Amaya, de Puebla).

Amaya chegou a Tijuana pretendendo apenas visitar a cidade e, em seguida, ir para casa. Mas, durante a viagem, ela começou a ter problemas e de repente não tinha os recursos financeiros para viajar de volta, cerca de $2.414 \mathrm{Km}$, para sua terra natal, no sul. No entanto, raramente são apenas problemas financeiros que levam as mulheres a entrar na indústria do sexo. Muitas têm a responsabilidade exclusiva de cuidar de crianças pequenas e outros membros da família. Ao mesmo tempo, muitas das mulheres que entrevistei não dispunham de certificados que comprovassem uma educação formal ou um ofício, o que torna impossível para elas entrar no mercado formal de trabalho e trabalhar em fábricas ou escritórios. Além disso, muitos empregos no

\footnotetext{
${ }^{8}$ A nova lei mexicana contra o tráfico humano, introduzida em 2012, proíbe toda a publicidade nos meios de comunicação que busca o contato sexual ou promove a prostituição e pornogafia que poderia facilitar o tráfico de pessoas. A sanção designada fica entre dois e sete anos de prisão e a multa entre Mex \$500 e 2000 (cerca de USD 34 e 136, 25 de janeiro de 2015). Ativistas trabalhadoras do sexo da Cidade do México criticaram esta lei duramente, porque inibe seriamente o trabalho sexual independente, obrigando as trabalhadoras do sexo, para continuar a exercer o seu ofício, a contratar intermediários profissionais, que mantêm ligações com o crime organizado ou funcionários públicos corruptos (Regeneración Radio, 2012).

${ }^{9}$ Os autores aqui calculam clubes noturnos em todo o espaço urbano de Tijuana, não só na zona de prostituição, que é muito menor.
} 
setor de serviços em Tijuana exigem conhecimento da língua inglesa e certificados de proficiência nessa língua. Na zona de prostituição, fazse dinheiro rapidamente, sem ter de provar competências ou qualificações.

A existência da indústria do sexo em Tijuana e sua possibilidade de que as mulheres ganhem muito mais do que no sul é amplamente conhecida entre as mulheres que vendem sexo em outros lugares no México. ${ }^{10}$ Mulheres discutem e divulgam informações sobre estabelecimentos de sexo de Tijuana e as respectivas condições de trabalho em diferentes clubes. Muitas vezes, é a circulação de histórias de sucesso que atrai outras mulheres para tentar a sua sorte na zona norte. Inspiradas pela experiência de amigas do sexo feminino, elas viajam em pares ou em pequenos grupos, determinadas a experimentar o trabalho sexual e a testar se podem lidar com a experiência. Em muitos casos, é apenas uma ou duas mulheres de um grupo que acabam por ficar e continuar a trabalhar no comércio do sexo. As outras decidem que não gostaram - de clientes, do ambiente ou do trabalho sexual em si - e voltam para casa para buscar outras oportunidades.

Histórias positivas sobre bons clubes de sexo se espalham rapidamente entre mulheres. Muitas delas tinham ouvido falar, muito antes de sua chegada, do célebre Adelita Bar, por exemplo, que foi recomendado por permitir ganhos elevados e por ter funcionários que tratam as mulheres com respeito. Quando Serena contou a suas amigas sobre suas experiências na zona norte, cinco mulheres imediatamente juntaram-se a ela e quiseram acompanhá-la para trabalhar na indústria do sexo em Tijuana.

A sedução da zona de prostituição em Tijuana deriva de vários fatores. A maior atração é claramente as enormes somas de dinheiro que podem ser obtidas de maneira informal e sem muita papelada, competências profissionais ou certificados. ${ }^{11}$ Além disso, os protocolos

\footnotetext{
${ }^{10}$ Ao estudar o trabalho sexual e violência de gênero na Cidade do México, em 1998/99, percebi que, na verdade, foi bastante comum que as profissionais do sexo do sul do México viajaram para o norte até Tijuana para períodos do ano, permitindo-lhes ganhar lucros mais elevados do que no sul (HOFMANN, 2005).

${ }^{11}$ Durante meu campo as mulheres cobraram entre USD 80 e 120 por coito vaginal; e mais por serviços especiais. Entre 2006 e 2008 o salário mínimo em Baja California era aproximadamente USD 6 por um dia inteiro de trabalho. Segundo os relatos das
} 
dos melhores estabelecimentos, em certa medida, asseguram a segurança das mulheres e protegem-nas da violência e do assédio da polícia ou dos clientes. Em terceiro lugar, as instituições de saúde em Tijuana emitem uma tarjeta sanitária, que atua como uma espécie de autorização de trabalho, o que permitiu a algumas mulheres sentirem que lhes foi conferido certo status oficial ${ }^{12}$.

Essas condições, juntas, contribuem para a relativa popularidade da indústria do sexo em Tijuana e são responsáveis pela atração contínua que a cidade exerce sobre as mulheres jovens de toda a república. A decisão das mulheres de entrar no trabalho sexual foi feita de um modo muito racional, auto-reflexivo e estratégico, calculando custos versus benefícios e avaliando as próprias capacidades e a vontade de se envolver no trabalho sexual. Amaya diz o que finalmente convenceu-a a vir trabalhar na zona norte:

Bem, eu tinha uma amiga que me disse que se pode fazer um bom dinheiro aqui sem ser tocado por clientes. Eu pensei:"isso é bom então", e disse:"tudo bem, se é verdade que os homens não vão me tocar, eu aceito", e então eu disse que eu iria (Amaya, de Puebla).

A história de Amaya mostra as diferentes etapas da sua decisão de se tornar uma profissional do sexo. Em primeiro lugar, uma pessoa em quem ela confiava forneceu as informações necessárias sobre as possibilidades e modalidades do trabalho sexual em Tijuana. Em segundo lugar, não ser tocada ou molestada por clientes era uma de suas pré-condições. Atuar apenas como uma stripper, no palco, sem contato físico direto com os clientes, era uma forma do trabalho de sexo que ela podia imaginar-se fazer. ${ }^{13}$ Não serem forçadas pelos gerentes do clube a realizar atividades específicas, estar no controle de

trabalhadoras sexuais, nos fins de semana foi possível conseguir entre 5-8 clientes por noite sem esforços extremos.

${ }^{12}$ Outras profissionais do sexo, no entanto, eram mais críticas dos cartões de saúde emitidos pelo governo, destacando os altos custos dos exames de saúde obrigatórios e da emissão e renovação constante do cartão. Elas também sentiram que deveria haver provedores de saúde alternativos do governo, esperando preços mais baixos de uma concorrência.

${ }^{13}$ Não muitas profissionais do sexo permanecem strippers, no entanto. Quando elas conhecem as realidades do comércio do sexo, percebem os enormes benefícios financeiros da prestação de serviços sexuais. Eles geram significativamente mais renda do que stripping, e as mulheres que estão interessadas em limitar seu tempo no trabalho sexual e, assim, ganhar muito dinheiro em um curto período de tempo, terão de vender sexo. 
seu trabalho e estabelecer as suas próprias condições para o que elas fazem e permitem aos clientes é importante para as mulheres que decidem se engajar no trabalho de sexo profissional.

\section{Nem todo mundo quer atravessar}

Em diversos momentos históricos, as pessoas têm explorado o que é o melhor ou o mais conveniente sistema legal em ambos os lados da fronteira EUA-México (CUEVA LUNA e VAZQUEZ GALAN, 2009). Atravessadores da fronteira México-EUA frequentaram os cassinos de Tijuana e salas de jogos durante a época da Lei Seca, por exemplo, enquanto no passado mais recente, mexicanos cruzaram para os EUA para usar os serviços de clínicas de aborto livre (REAGAN, 2000). Há uma inter-relação histórica forte em toda a zona fronteiriça, em termos de negócios, serviços públicos e de lazer, e, consequentemente, a vida cotidiana em Tijuana sempre esteve diretamente afetada pela situação política, jurídica e econômica dos Estados Unidos.

Várias centenas de milhões de cruzamentos de fronteira ocorrem cada ano, a maioria dos quais são realizadas por residentes da metrópole transfronteiriça Tijuana-San Diego (HERZOG, 2003). A globalização abriu territórios fronteiriços para novas formações da comunidade, com os consumidores constituindo o grupo mais ativo dos atravessadores legais da fronteira, e talvez a população principal que liga os dois lados da metrópole (MURIA TUÑóN, 2010). Os cidadãos de cada lado da fronteira são cada vez mais atraídos juntos, e, como vizinhos urbanos, tornam-se parte de uma vida transnacional comum e um só espaço de trabalho (CHÁVEZ, 2007). Em ambos os lados da fronteira EUA-México, há um número significativo de cidadãos transnacionais, pessoas que fazem uso de recursos socioeconômicos de ambos os lados da fronteira, e estabelecem redes sociais através da fronteira nacional. Dependendo de sua situação legal, elas podem ser capazes de exercer direitos políticos em mais de um Estado-nação (SMITH e BAKKER, 2008). Cidadãos transfronteiriços formam uma rede complexa regional de fluxos através da fronteira. Eles contribuem para a construção de vínculos entre as cidades fronteiriças Tijuana e San Diego através da comutação internacional, o consumo e o uso de mercados transfronteiriços, o trabalho em fábricas globais, e o 
intercâmbio cultural (ANGUIANO TELLEZ e HERNÁNDEZ MADRID, 2002). Revistas semanais, por exemplo, fornecem informações sobre eventos culturais, como concertos, palestras, conferências, feiras e combates de luta livre em San Diego, e viceversa. Atravessadores da fronteira transformam a zona fronteiriça em um espaço transnacional, através de suas práticas cotidianas, e sua participação na vida social, cultural e consumista em ambos lados da fronteira. No entanto, nem todo mundo pode ou quer atravessar a fronteira.

Apesar de múltiplos cruzamentos de mexicanos de ambos os lados, a barreira geopolítica que divide México e os Estados Unidos não pode ser considerada totalmente permeável como às vezes parece sugerir a literatura extensa sobre migração transnacional no contexto EUAMexico (para mencionar algumas obras: HIRSCH, 2003; SCHAEFFER-GABRIEL, 2003; SEGURA e ZAVELLA, 2007; RIVERA-SALGADO, 1999; VELASCO ORTIZ, 2005; WILSON, 2009). A fronteira com México continua a ser uma barreira excludente para muitos cidadãos de ambos os lados que não conseguem usar a região fronteiriça como um espaço transnacional.

Muitas das mulheres com as quais eu falei tinham atravessado a fronteira para os EUA no passado para o trabalho ou para visitas de familiares. Porém, ter a chance de atravessar a fronteira livremente no tempo desejado é um marcador de distinção na fronteira. A possibilidade de cruzar a fronteira é um capital que se possui ou não. Assim, perguntar às pessoas sobre seus cruzamentos pessoais da fronteira é um assunto sensível, porque o padrão de cruzamento revela o status social ao mesmo tempo.

De requerentes de certos vistos ${ }^{14}$ as autoridades de imigração encomendam, por exemplo, a submissão de um contrato de emprego,

\footnotetext{
${ }^{14} \mathrm{Um}$ tipo de visto que é muito valioso na fronteira é o B1/B2 visto para visitantes ou a Border Crossing Card. É um visto não imigrante para estadia temporária que permite negócios, turismo, lazer ou visita, ou uma combinação deles. É um visto de entrada múltipla e geralmente válida por dez anos após a emissão. Apesar de estudo, emprego e trabalho serem atividades excluídas, a Border Crossing Card é usada para trabalhar informalmente em setores como o trabalho doméstico, trabalho nos bastidores da hospitalidade, jardinagem e vários outros tipos de trabalho manual. Os candidatos devem ser cidadãos mexicanos ou comprovar residência no México. Para atender às normas de elegibilidade para os vistos B1/B2, os candidatos devem demonstrar que têm vínculos com o México que iriam obrigá-los a voltar depois de uma estadia temporária nos Estados Unidos. Geralmente, a prova de emprego e/ou
} 
provando que têm uma renda permanente, o que é impossível para quem trabalha em trabalhos freelance ou no mercado de trabalho informal. Os funcionários da imigração podem também verificar extratos bancários e comprovantes de propriedade privada. Segundo os relatos de muitos Tijuanenses com os quais falei, ter membros da família que possuem um terreno ou uma casa melhora consideravelmente as chances de adquirir um visto, isto sendo considerado evidência para um "vínculo" com o México que iria "obrigar" os visitantes a voltar. Uma vez que a própria trajetória do cruzamento da fronteira revela detalhes sobre a posição socioeconômica do indivíduo e sua conexão com pessoas que possuem capital, muitas pessoas não querem falar sobre seus movimentos transfronteiriços ou mesmo expressam uma aversão ou rejeição desse foco exagerado na fronteira que prevalece em Tijuana.

Muitas profissionais do sexo com as quais falei insistiram em que elas não estavam interessadas em cruzar a fronteira para os Estados Unidos. Elas se distanciaram de um interesse em viver no país vizinho, como expressa Débora aqui:

Eu já estive lá [nos Estados Unidos]. É aí que eu tive a minha filha. Minha mãe me disse que eu não deveria sair mais quando eu já estava nas últimas semanas da minha gravidez. Mas eu fui e depois começaram as contrações e tive a criança lá. Eu vivi em Chula Vista, Lancaster e Los Angeles. Estava bem lá, mas a vida é apenas o mesmo que aqui - mexicanos em todos os lugares (Débora, 22 anos, de Tijuana).

laços familiares são suficientes para mostrar a finalidade da viagem e a intenção do requerente para retornar a seu país de origem. No entanto, na realidade, muitos candidatos são convidados a fornecer documentação adicional, especialmente se suas situações de vida ou suas famílias desviam da norma, por exemplo, se eles são trabalhadores por conta própria ou se sua família não tem um "provedor" ou chefe masculino da família. Para os mexicanos que possuem um passaporte dos EUA ou um Certificado de Naturalização, existem diferentes tipos de programas de viajantes confiáveis, tais como SENTRI (Rede Eletrônica Segura para Inspeção Rápida de Viajantes), que permite que viajantes pré-selecionados sejam processados de forma acelerada quando entrarem nos Estados Unidos em portos fronteiriços designados, e FastLane, que é um passe especial para turistas, criado em particular para o fim de turismo médico. Apenas viajantes pré-aprovados, de baixo risco podem obter um cartão de SENTRI, e os inscritos devem enfrentar verificações rigorosas de seus antecedentes, que incluem seguro de carro, declaração de imposto, alvará de funcionamento, extratos bancários, pagamentos de hipoteca e aluguel e pagamentos de contas de utilidade entre outros. 
Nas interações sociais cotidianas, as capacidades de cruzamento da fronteira tornam-se muito evidentes. Por exemplo, aqueles que podem atravessá-la usam roupas diferentes, compradas no shopping "Las Américas" de San Ysidro no lado dos EUA, apenas trezentos metros da cerca fronteiriça, e praticamente em frente da zona de prostituição. As identidades sociais de atravessadores da fronteira são baseadas em suas experiências e práticas cotidianas em dois espaços nacionais (ANGUIANO TELLEZ e HERNÁNDEZ MADRID 2002; MARTÍNEZ, 1994; VILA, 2007). Atravessadores da fronteira falam sobre diferentes eventos culturais e sociais, como concertos ou festivais em que participaram no outro lado. Frequentes atravessadores da fronteira, com ligações familiares no outro lado, possuem conhecimentos diferentes, usam uma linguagem diferente, e desenvolvem identidades diferentes de alguém que não pode atravessar a fronteira ${ }^{15}$.

Assim, o cruzamento da fronteira significa privilégio, vantagens econômicas e ganhos pessoais. Compreensivelmente, algumas pessoas que vivem na zona de prostituição em Tijuana, colada à cerca da fronteira, mas que nunca tiveram a chance de entrar nos Estados Unidos, distanciam-se com veemência deste símbolo de status de zonas fronteiriças, como Letícia expressa aqui:

Na verdade, eu não gostaria de viver nos Estados Unidos. Eu não desejo ir para lá. Eu não tenho documentos e não quero eles. Gostaria de cruzar o Atlântico para trabalhar

\footnotetext{
${ }^{15}$ Numerosos estudiosos explicaram o que acontece com a cultura e a identidade quando o enraizamento em um ambiente cultural único não é mais dado, indicando como as identidades estão sendo moldados através da experiência de migração (CISNEROS, 2014; FORTE 2010LATTANZI SHUTIKA 2011; SMITH e BAKKER, 2008; STEPHEN, 2007; VALERIO-JIMÉNEZ, 2013). Ao entrar em um ambiente cultural diferente e ser expostas a novas influências ao seu redor, as pessoas se transformam e estão sendo transformadas, gerando novas identidades através da formação de novas alianças, utilização de redes transnacionais e acesso a recursos de dois espaços culturais e políticos. Laura Velasco Ortiz $(2005,2008)$, por exemplo, examinou a formação da identidade étnica nas condições de migração internacional, destacando a formação de uma consciência étnica surgindo da experiência de ser imigrante nos Estados Unidos. O que eu quero enfatizar aqui é que o cruzamento frequente da fronteira permite que os saberes, a linguagem e as identidades dos individuos gradualmente tornar-se híbridos, no sentido de ser gerado de diferentes contextos culturais. Por exemplo, atravessadores frequentes da fronteira vão ganhar uma melhor compreensão do Inglês, muitos deles usando cada vez mais Spanglish (i.e. uma mistura de Espanhol e Inglês) na comunicação cotidiana (BEJARANO, 2007), muito parecido com os chicanos (i.e. mexicanos-americanos nascidos nos Estados Unidos).
} 
na Europa e conhecê-la, mas os Estados Unidos, não. Eu não gosto. Parece o mesmo que aqui. Eu não gosto (Leticia, 38 anos, da Cidade do México).

Resistir ao hype-fronteiriço (border hype) ${ }^{16}$ também significa resistir ao valor simbólico que ele contém. É uma depreciação do fato de que é melhor viver lá ou ser capaz de ir para lá. Para Letícia, os Estados Unidos não são muito atraentes. Ela deseja viajar para outro lugar; assim, ela descentra e diminui o significado hegemônico dos Estados Unidos na zona fronteiriça. Histórias de cruzamento da fronteira são às vezes também histórias de ressentimento, em que os pais cruzaram-na deixando os filhos para trás, ou membros da família estabeleceram uma vida nos EUA, mas não se preocuparam mais com aqueles que continuaram a viver no México. A fronteira como uma divisão física, geoestratégica, também produz divisões internas e emocionais que se refletem na realidade da vida das pessoas e nas narrativas.

As trabalhadoras sexuais que se distanciam do "troféu fronteira", a capacidade de atravessar, ativamente resistem à degradação contínua de suas vidas como não atravessadores, ou "meras" moradoras em Tijuana e destacam que seus próprios interesses e desejos têm um outro foco. Gloria Anzaldúa (1987), uma pioneira da teorização da fronteira no contexto da zona fronteiriça EUA-México, descreveu a fronteira como um local conceituado e produzido a fim de gerar divisões, entre pessoas, territórios e culturas. A designação da fronteira

\footnotetext{
${ }^{16} \mathrm{O}$ prefixo "hyper" significa "excessivo", "indevido", derivado do uso prefixal grego de "hypér", que é "mais" ou "acima". Aqui me refiro à importância inflada da fronteira, e em particular do cruzamento da fronteira, da entrada no espaço territorial dos Estados Unidos, visando desafiar a noção de cruzamento da fronteira, o seu significado generalizado, elevado e os imaginários, muitas vezes embelezados que ela implica. Para Tijuanenses a fronteira é evidentemente presente na vida cotidiana (rádio, notícias, mídia) e faz parte do imaginário cultural (literatura, arte, música, cinema); uma infinidade de exemplos poderiam ser nomeados aqui. Produções culturais têm desempenhado um papel significativo tanto nas histórias que retratam de cruzamentos de fronteira, quanto na alimentação de imaginários de migração para o norte e da entrada do território norte-americano. Manifestações de travessias em produções culturais da zona fronteiriça dos EUA-México também tendem a priorizar retratos da fronteira como local de dinamismo, flutuação, movimento, cruzamentos, mixagem e hibridismo, juntamente agrupando o cruzamento da fronteira com o desejo, a moda, e o status, alimentando assim o fascínio da fronteira e do cruzamento da fronteira. Até agora houve poucas tentativas para ilustrar empiricamente como cruzamentos e o hibridismo alcançado através de cruzamentos estão interligados com as condições materiais das pessoas. Uma exceção é Theodore Karwoski Gideonse (2007), por exemplo, quem examina como o hibridismo na fronteira EUA-México pode se tornar em capital cultural.
} 
torna possível “distinguir nós dos outros” (ANZALDÚA 1987, p. 3). Para Anzaldúa fronteiras são o resultado de projetos políticos inerentemente violentos, que têm a função intrínseca de produzir dicotomias. Na minha interpretação, a dissociação das mulheres do hype-fronteiriço, significa uma rejeição das dicotomias que são continuamente reproduzidas e solidificadas na fronteira EUA-México, como atravessador/não atravessador, beneficiado/não beneficiado, avançado/atrasado e poderoso/impotente.

Para muitos profissionais do sexo que vieram para Tijuana, no entanto, a própria fronteira é o foco da atração. Elas viajaram centenas de quilômetros para o norte, com a intenção de ganhar dinheiro lá. A fronteira em si é um recurso para elas, uma "mina de ouro" da qual pretendem obter a sua quota. Delia (33 anos, de Ensenada) esclarece: "A melhor coisa sobre Tijuana é que sempre há turistas, sempre há dinheiro”. Para Delia, Tijuana é um lugar onde há dinheiro, e é preciso saber como aproveitar dele. Tijuana é um lugar aonde as pessoas vêm com o fim de fazer dinheiro rápido e, em seguida, voltar para casa, com melhores oportunidades para um futuro mais próspero. Muitas das

profissionais do sexo que vieram para trabalhar na cidade não têm a intenção de ficar lá. Elas querem aproveitar o que a cidade oferece e, em seguida, avançar suas vidas. Sua estadia na fronteira é muitas vezes apenas temporária. No entanto, na zona fronteiriça, as mulheres entram em uma localização ambivalente, carregada de conflitos e às vezes perigosa, onde as oportunidades de empoderamento pessoal coincidem com múltiplas vulnerabilidades.

\section{Insegurança espacial em uma cidade de fronteira}

Henri Lefebvre salientou que o espaço é sempre socialmente construído e que cada sociedade produz um espaço que é adequado para a sua própria reprodução (1991). Historicamente, o trabalho sexual tem sido restrito a áreas marginais que expõem sujeitos envolvidos ao perigo e incentivam uma associação entre a imoralidade, violência, doença e pobreza. Hubbard e Sanders (2003, p. 79) apontam que, "essa marginalização de prostitutas, não só no discurso moral, mas também geograficamente em 'ruas de vergonha' cria, assim, uma geografia moral que implica que alguns comportamentos são aceitáveis apenas em determinados lugares". 
Distanciando o trabalho sexual do centro social, político e econômico de uma cidade fisicamente e discursivamente, uma hierarquia social é mapeada sobre o espaço. $\mathrm{O}$ trabalho sexual tem sido muitas vezes percebido como uma perturbação da ordem socioespacial e, portanto, deve ser escondido do olhar dos cidadãos respeitáveis. Isso produz uma representação dominante do espaço que sugere que o sexo comercial é desviante, poluente e perigoso; uma aberração em sociedades que valorizam a santidade da família (HUBBARD; SANDERS, 2003, p. 83).

$\mathrm{Na}$ parte seguinte deste artigo, quero olhar para um aspecto da experiência das mulheres na fronteira EUA-México que tem sido relevante em muitas narrativas das profissionais do sexo, que é a experiência de insegurança. Vou descrever que a insegurança espacial $^{17}$ na zona de prostituição de Tijuana é produzida por dois grupos principais de atores: 1) indivíduos que são vítimas de políticas de militarização de fronteira, e 2) autoridades do Estado.

Historicamente, a zona de prostituição de Tijuana tem sido o lugar onde os migrantes, provenientes da América Central e do sul do México, fazem contato com os coyotes que irão guiá-los através da fronteira (PRICE, 1973; CURTIS; ARREOLA 1991). No entanto, nos últimos vinte anos, as dinâmicas sociais e econômicas na zona de fronteira EUA-México, foram fortemente alteradas como um efeito dos esforços dos EUA para aumentar a segurança na fronteira. A securitização da fronteira foi atingida por meio de vários programas governamentais, como por exemplo a operação Hold the Line em 1993, que, em vez de focalizar o controle nos pontos de fronteira, tentou capturar os migrantes sem documentos nas áreas de deserto, principalmente afetando a zona fronteiriça perto de Ciudad Juárez/El Paso. A operação Gatekeeper ${ }^{18}$ em 1994 liberou investimentos imensos em recursos humanos, aumentando o pessoal da Patrulha de Fronteira (Border Patrol), e iniciou a construção do muro fronteiriço (border wall ou border fence). A operação Streamline, no setor Tucson da fronteira em 2005, foi um programa que visou ao encarceramento

\footnotetext{
${ }^{17}$ Insegurança espacial: um espaço geográfico, no qual corpos de gênero (gendered bodies) e corpos sexualizados experimentam insegurança relacionada com o que a sua presença encarnada (embodied) significa nesse espaço geográfico particular.

${ }^{18}$ Para uma descrição detalhada da implementação do programa OperationGatekeeper e seu efeitos para migrantes recomendo (NEVINS, 2002).
} 
em massa de pessoas sem documentos para reduzir as tentativas repetidas de migração (BURRIDGE, 2009).

A fortificação e o aumento da vigilância das fronteiras têm provocado uma situação em que muitos migrantes sem dinheiro ficam presos em Tijuana. As políticas de imigração dos EUA causam um fluxo crescente de imigrantes deportados, os quais chegam à zona de prostituição que fica a dez minutos do posto de fronteira. Duas décadas atrás, as pessoas teriam se preparado imediatamente para uma segunda tentativa de atravessar a fronteira. Mas o seu cruzamento foi empurrado cada vez mais para o leste - no deserto - tornando a viagem muito mais perigosa e cara para os migrantes, estendendo o tempo que passam no lado mexicano da fronteira tentando juntar dinheiro para uma outra travessia.

Assim, a zona de prostituição de Tijuana é caracterizada por pessoas que têm uma necessidade de fazer dinheiro imediatamente, muitas das quais têm pouca educação formal ou possibilidades para entrar no mercado formal de trabalho. A maioria dos moradores da zona norte tenta ganhar a vida com atividades relacionadas de alguma forma à indústria do sexo, por exemplo, como diaristas, vendedores ambulantes, vendedores de comida, garçons, guardas de segurança ou cabeleireiros. Todos tentam se beneficiar de alguma forma dos lucros das trabalhadoras sexuais, fornecendo serviços essenciais para elas.

As trabalhadoras sexuais ganham somas significativas de dinheiro na zona norte. Elas são, com exceção dos traficantes de droga e os donos de estabelecimentos, as mais ricas, o que ao mesmo tempo as tornam vulneráveis a roubos e à agressão violenta. Essa vulnerabilidade tem de ser entendida no contexto econômico local: o salário mínimo durante meu trabalho de campo era ao redor de USD 6 por dia, enquanto as trabalhadoras do sexo podiam ganhar mais de USD 1.000 em uma noite boa. Muitas das trabalhadoras sexuais que trabalham em bares e clubes de classe alta ${ }^{19}$ entram e saem da zona com seus próprios carros, o que significa que elas têm de caminhar até o estacionamento mal iluminado na margem da zona de prostituição.

\footnotetext{
${ }^{19} \mathrm{Me}$ refiro aqui a bares e clubes refinados que pretenden atrair clientes ricos através de um ambiente exclusivo (e.g. decoração nova e chique), oferecendo uma seleção de mulheres requintada (mais jovem e linda do que nos outros locais). Enquanto as boates de classe alta cobram preços elevados dos clientes (entrada, drinques, taxa da saída) também fornecem a oportunidade de ganhar mais dinheiro às mulheres.
} 
Outras, se podem, convencem um namorado a recolhê-las, ou pegam uma carona de um colega. Algumas mulheres compartilham táxis para casa, mas isso tem os seus perigos nas primeiras horas da manhã. Apesar de trocarem de roupa depois de um turno de trabalho, o fato de que elas são profissionais do sexo é difícil de esconder, porque a mera presença de mulheres nesse espaço e nessas horas do dia, revela a sua profissão provável.

No caso de se deslocar de taxi, para evitar serem atacadas e roubadas por um taxista desconhecido, as mulheres tentam desenvolver relações com motoristas particulares que elas possam chamar sempre quando precisarem de uma carona. ${ }^{20}$ As trabalhadoras do sexo de rua que vivem e trabalham na zona norte são, provavelmente, os indivíduos mais vulneráveis, porque têm de caminhar a pé para casa atravessando becos estreitos e escuros, levando seu dinheiro recém ganho em suas roupas ou suas bolsas. Como o corpo é o único esconderijo para o dinheiro que elas lucraram durante a noite, as profissionais do sexo devem desenvolver estratégias para chegar em casa com segurança sem serem roubadas.

Em toda a zona norte é perigoso, para ser honesta. Agora, uma vez que a economia está em baixa, não nos faltam vigaristas que querem roubar de nós, para dizer a verdade. Pode ser um conhecido de lá - bem, é por isso que não podemos confiar [...] É por isso que nós acompanhamos umas às outras em nosso caminho para sair da zona (Rosalía, 29 anos, a partir de Puebla).

Profissionais do sexo da rua, como Rosalía, alugam quartos baratos na zona de prostituição e muitas vezes vivem em quartos minúsculos com apenas uma cortina pendurada em frente à entrada. ${ }^{21}$ Por isso mesmo, uma vez que chegam em casa, é difícil para elas guardar seu dinheiro com segurança. Como uma fonte significativa de insegurança, as

\footnotetext{
${ }^{20}$ Esta é uma estratégia feminina comum para lidar com a insegurança local e o perigo em Tijuana, e não é exclusivamente usada por profissionais do sexo. Até o final do meu trabalho de campo eu conhecia pessoalmente vários taxistas confiáveis e amigáveis aos quais liguei quando necessário; entre eles, havia motoristas de táxi do sexo feminino, amigos de amigos (repassados por amigas) e motoristas de táxi que eu conheci durante passeios diurnos e em quem confiei suficientemente para pedir seus números de telefone.

${ }^{21}$ Esses lugares são chamado cuarterías, que são prédios com quartos individuais separados do quintal coletivo por uma cortina. Os quartos geralmente têm banheiro, mas nem cozinha, nem chuveiro. Os moradores têm acesso a um poço coletivo localizado no meio do quintal de onde transportam a água que precicam com baldes.
} 
mulheres identificaram os cholos $^{22}$ residentes em seu bairro. Eles são jovens de origem mexicana, residentes indocumentados de longa duração nos Estados Unidos e que, eventualmente, foram deportados dos EUA. Eles têm geralmente poucas qualificações formais e poucas ou nulas redes sociais para começar uma vida no México. As mulheres tinham uma aversão forte contra a cultura territorial de gangues que os cholos trouxeram e introduziram no México, apropriando-se do território da zona norte para seu benefício. Seus conhecimentos da língua inglesa lhes facilitam empregos na indústria do sexo como guardas de segurança, barkers ${ }^{23}$, talacheros $^{24}$ ou garçons. Sofía descreve sua aversão contra os cholos da zona norte e suas práticas:

A zona norte é perigosa. Uma [mulher] arrisca muito aqui. Há muitas pessoas - você caminha e eles pegam sua bolsa. Eles simplesmente derrubam as pessoas. Não, não é seguro aqui. Há pessoas que só andam por aí roubando. Você não pode escapar deles. Mas temos que tentar ser

\footnotetext{
${ }^{22}$ A palavra cholo tem significados divergentes em diferentes contextos culturais na América Latina. Refiro-me ao significado de cholo como derivado do contexto da zona de fronteira México-EUA. A palavra foi usada historicamente ao longo da fronteira como um termo depreciativo para significar imigrantes mexicanos nos Estados Unidos de classe baixa. Sendo que um cholo é freqüentemente associado com membros de gangues, um estilo de roupas distinto, corpos fortemente tatuados, linguagem e sinais de mão idiossincráticos, bem como com dureza e violência. Um forte sentido de territorialidade e brigas entre as gangues por territórios na cidade são considerados característicos de cholos nos Estados Unidos. Apesar de sua longa história de semântica denegrinte, o termo cholo foi transformado em algo positivo e usado como um símbolo de orgulho no contexto dos movimentos de poder étnico da década de 1960. O sociólogo mexicano José Manuel Valenzuela Arce descreve a cultura cholo como "cultura[s] de sobrevivencia, de escasez, de indefensión. Es la manera elemental, pedestre, de respuesta ante la crisis estructural que les ha tocado vivir" (VALENZUELA ARCE, 1988, p. 214). Enquanto ele descreve as vidas dos cholos como brutalmente imersas na violência, na delinquência organizada, e no tráfico de drogas, tornando a mobilidade social impossível, ele destaca as influências estruturais nas identidades deles, como a pobreza, a falta de emprego ou o subemprego, assédio policial arbitrário, a corrupção e o racismo. Ao me referir à análise detalhada empírica e historicamente contextualizada desta cultura de jovens mexicano-americanos, analisada por Valenzuela Arce, quero me distanciar de conceptualizações essecialistas de cholos como criminosos e traficantes por definição. No contexto de campanhas contra o tráfico humano, os cholos tornaram-se uma figura proeminente em seminários e capacitações de sensibilização nos EE.UU., uma tendência preocupante que pode levar ao aumento da discriminação e do racismo contra este grupo já estigmatizado.

${ }^{23} \mathrm{Um}$ barker é uma pessoa posicionada fora dos clubes do sexo com a tarefa de atrair clientes.

${ }^{24}$ Talacheros são homens que levantam as mulheres no palco (não sempre é necessário) e guardam o dinheiro ganho durante um show de striptease. Desse dinheiro eles ganham uma parte.
} 
mais cuidadoso. Agora, existem todos esses cholos, todos esses bandidos [...] Eles chegam aqui e encontram um refúgio aqui [na zona norte]. A gente tem de tomar cuidado e tentar ficar fora de problemas (Sofía, de 53 anos, de Puebla).

Alguns dos cholos e outros atores empobrecidos presentes na zona norte se especializaram em detectar as mulheres que obtêm rendimentos elevados, observando quantos clientes elas levam para o hotel para assaltá-las mais tarde. Outros moradores da área vivem de denunciar as mulheres que atendem clientes fora dos seus locais de trabalho sem que eles tenham pago a taxa do clube. Outros tentam convencer trabalhadoras sexuais jovens da necessidade da sua proteção com a intenção de acessar, dessa forma, os recursos de que elas dispõem. Tendo a possibilidade de gerar ganhos altos, as trabalhadoras sexuais têm se tornado uma oportunidade de geração de renda para outros. Conscientes da existência de tais sujeitos abusivos presentes na zona norte, muitas das trabalhadoras sexuais com as quais falei durante minha pesquisa eram atentas para não se relacionar com um deles.

A restrição do trabalho sexual para áreas marginais, caracterizadas pela extrema escassez de recursos da população local e pela presença de atores criminosos, pode ter profundas implicações para a saúde e segurança das trabalhadoras do sexo. Neil Smith (1996, p. 74) indica tais espaços de que tanto a autoridade cívica como a sociedade civil têm retirado a sua atenção, como "espaços de vulnerabilidade".

\section{Práticas extra-legais por parte das autoridades do Estado}

Mais difícil é evitar os abusos executados por autoridades do Estado mexicano. Na zona de prostituição de Tijuana, as práticas extra-legais das forças policiais contribuem significativamente para a experiência de insegurança espacial que vivem as trabalhadoras sexuais na zona de prostituição de Tijuana. As trabalhadoras do sexo expressaram uma profunda desconfiança em relação ao governo e suas instituições e órgãos executivos, como a polícia.

Acho que o maior risco é cair nas mãos da polícia. A polícia é mais perigosa do que qualquer coisa que possa acontecer nos bares. A polícia aqui em Tijuana é terrível [...] Os policiais são muito abusivos, e você não pode 
controlá-los. (Paula, 20 anos, de Monterrey).

A polícia só chega [na zona norte], a fim de roubar. Quando virem alguém parado na rua, eles revistam-no, e quando virem alguém carregar dinheiro, então eles forçam-no a entrar no carro da polícia. Eles levam-no, tomam o seu dinheiro e, em seguida, deixam-no ir. [...] Isso é como a polícia é. Sempre tem sido assim com a polícia aqui. [...] Você não pode se proteger contra a polícia, isso é impossível. [...] Quando se aproximado Natal ou do aniversário de alguém, eles dizem que têm de fazer algum dinheiro (Telma, 34 anos, de Tijuana).

As mulheres relataram as práticas policiais em Tijuana como abusivas e corruptas. É bem conhecido entre as profissionais do sexo que os policiais são obrigados a pagar a seus superiores uma certa porcentagem de seus "ganhos" após cada patrulha na cidade. Os agentes da polícia prendem regularmente profissionais do sexo por não possuírem ou levarem consigo a autorização de trabalho (a tarjeta sanitária) validada. Ao fazê-lo, a polícia age além da sua autoridade. Somente os funcionários governamentais de saúde são autorizados para controlar cartões de saúde e eles não têm nenhuma autoridade para prender as mulheres, mas apenas para retirar cartões inválidos.

Algumas profissionais do sexo trabalham em um estado de maior desproteção do que outras. Incluídas neste grupo estão profissionais do sexo não registradas que não possuem cartões de identificação válidos. Os policiais tomam em custódia mulheres encontradas sem autorização de trabalho válida, geralmente por até 36 horas. Algumas são levadas a um tribunal. As mulheres contaram que os juízes podem ser subornados, com valores variando entre 50 e 500 dólares, dependendo de quanto se estima que uma mulher específica pode pagar, com base em sua idade e beleza corporal. A desproteção das trabalhadoras sexuais não registradas é um efeito do regulamento do trabalho sexual em Tijuana. As trabalhadoras sexuais com rendas mais altas, geralmente as que trabalham nos clubes e bares, em geral não estão sujeitas a esse tipo de assédio da polícia, porque elas podem arcar com os custos contínuos dos exames de saúde obrigatórios. No entanto, todas as mulheres que vendem sexo na zona norte estão conscientes das práticas extra-legais da polícia local e da corrupção.

Muitos estudiosos têm descrito o contexto sociogeográfico da fronteira mexicano-americana como um espaço caracterizado pela violência, a corrupção e a impunidade da polícia mexicana, produzindo um 
ambiente que expõe as mulheres, em especial, a altos níveis de insegurança e vulnerabilidade (STAUDT, 2008; ALFARACHE LORENZO, 2009). A feminista mexicana Marcela Lagarde aponta que as mulheres na zona fronteiriça EUA-México vivem "sem segurança social ou institucional, em zonas de devastação, onde a insegurança e o crime dominam, a convivência é marcada pela ilegalidade e pela lei da rua, onde as instituições têm perdido o controle, e o Estado de direito é quebrado" [traduzido do alemão pela autora] (LAGARDE, 2005, p. 8 apud ALFARACHE LORENZO, 2009, p. 109).

Na mesma linha, Kathleen Staudt (2008), que estudou o fenômeno dos feminicídios na fronteira EUA-México, afirma que a violência contra as mulheres e sua impunidade são os problemas fundamentais na fronteira. Ela descobriu que a resposta institucional do México à violência contra a mulher tem sido escassa, independentemente do florescimento de organizações de mulheres e de direitos humanos na fronteira $^{25}$. Para Staudt, a resposta para a vulnerabilidade das mulheres à violência na fronteira está na configuração institucional:

'As instituições políticas e a polícia afetam a incidência de crime. As instituições são influídas por gênero [ingl. gendered], absorvendo características sociais de homens e mulheres, desde o nascimento organizacional até seus atuais modos de operação (LOVENDUSKI, apud STAUDT, 2008, p. 05)

Ainda de acordo com o autor, "Organizações quase-militarizadas, as agências policiais são mais dominadas por homens do que a maioria das instituições governamentais" (STAUDT, 2008, p. 5). Para Staudt, instituições de governança e de justiça criminal fracassadas são diretamente responsáveis por e cúmplices com a insegurança e exposição à violência que as mulheres experimentam na fronteira. Ela observou a falta de empenho político para a aplicação da lei na região fronteiriça, sugerindo que as organizações da sociedade civil evitam o Estado, ao invés de interagir com ele.

Alguns estudiosos sustentam a visão histórica da região fronteiriça EUA-México como uma periferia lendária e sem lei, em que bandidos encontram um porto seguro. Lydia Cacho, feminista mexicana,

${ }^{25}$ Seu argumento baseia-se no estudo internacional de Laurel Weldon sobre a capacidade de resposta de governos à violência contra as mulheres. Aquele estudo descobriu que, sempre onde movimentos sociais ativos existiam, pressionando para mudanças de políticas, os governos eram mais ágeis. No entanto, isso não foi assim no caso dos feminicidios de Ciudad Juarez. 
jornalista e ativista dos direitos humanos, define as regiões fronteiriças como uma

zona que é uma terra de ninguém, geralmente selvagem, remota, pouco povoada, não sujeito a controle político; onde todo mundo toma a lei em suas mãos e faz justiça de acordo com suas próprias paixões; onde naturalmente todos os tipos de vícios florescem, incluindo, em primeiro lugar, claro, a corrupção, seguido pela violência impune, poder, abuso, engano, fraude, etc. (CACHO, 2006, p. 24).

Cacho descreve a fronteira como um espaço que carece de institucionalidade e onde a justiça continua instável:

O resultado é uma organização social caracterizada por sua institucionalidade escassa, pela precariedade da justiça e por um estilo de gestão social construído sobre caciquismo, a intervenção pessoal e o peso decisivo da vontade e da idiossincrasia de atores. Com maior intensidade do que no resto do país, a sociedade civil nesta região encontra-se sem armas, sem instituições de peso para enfrentar o aparelho do poder que representa a fusão de intermediários enriquecidos e os políticos dos usos e costumes tradicionais. Enfrentando um vazio institucional, as redes de solidariedade social estão construindo-se (CACHO, 2006, p. 26$)^{26}$.

Ambas - Staudt e Cacho - culpam as instituições estatais deficientes em regiões fronteiriças como razões para a insegurança que as mulheres lá experimentam e sua vulnerabilidade à violência. Elas argumentam que, por não perseguir a violência contra as mulheres, tais como os feminicídios, por exemplo, não aplicar a lei, não treinar a polícia de forma adequada, e não se comprometer com as demandas das organizações da sociedade civil, o Estado anuncia o comportamento sem lei contra as mulheres e, concomitantemente, vitimiza-as. Ambas estudiosas veem o Estado na fronteira como enfraquecido e corrompido pelas redes criminosas de traficantes de drogas que com suas redes difundidas em todos os grupos sociais da região de fronteira infiltraram as instituições estatais e conseguiram consolidar suas práticas e códigos de conduta dentro das instituições do Estado.

\footnotetext{
${ }^{26}$ Quando Lydia Cacho menciona "usos e costumes" aqui, ela refere-se a políticos "tradicionalmente" corruptos, em vez do que o que normalmente se entende com o termo em México, a lei comunitária indígena.
} 
Essas explicações para a violência em zonas de fronteira têm em comum um grande nível de confiança no Estado e suas capacidades para governar e estabelecer proteção para os grupos vulneráveis da sociedade. Muitas profissionais do sexo não compartilham dessa confiança. Profissionais do sexo são um grupo de cidadãos marginalizados, para quem as instituições do Estado até agora não têm feito nada significativamente positivo para atender às suas necessidades ou aumentar o seu bem-estar. Muitas profissionais do sexo têm crescido em espaços de exclusão, espaços socialmente marginalizados que carecem de impactos positivos das instituições governamentais. Em conversa comigo, as mulheres expressaram sua falta de confiança nas instituições e órgãos executivos do governo, que foi relacionada a experiências negativas no passado. Muitas profissionais do sexo, como suas famílias, nunca experimentaram instituições democráticas como benéficas para elas. Em muitas das suas cidades de origem, as autoridades locais foram igualmente corruptas e cobraram suborno para serviços. Muitas profissionais do sexo que vêm para a zona fronteiriça têm perdido a confiança na utilidade das instituições civis e a integridade dos líderes políticos há muito tempo. A trabalhadora do sexo Naima expressa sua frustração, desilusão e dissociação do governo:

Eu não espero nada do governo. Não tenho nenhum interesse no que eles dão ou não dão. Eu não espero obter nenhuma coisa do governo. É o governo que ganha das pessoas (Naima, 26 anos, de Ensenada).

Algumas pesquisas têm enfatizado que em todo México (não só na região de fronteira) o Estado de Direito não é aplicado, que as suas instituições de justiça criminal obram mal (BAILEY e CHABAT 2002; DOMINGO, 1999; HUMAN RIGHTS WATCH, 1999), e que os cidadãos em diferentes regiões do país expressam desconfiança generalizada da polícia. As autoridades policiais no México têm geralmente baixas quotas em reduzir o crime e os índices de criminalidade, e existem poucos incentivos burocráticos para investigar o crime (ZEPEDA LECUONA, 2002).

Alguns estudiosos oferecem uma perspectiva diferente sobre as margens territoriais, contestando a ideia de que os estados ficam enfraquecidos nesses lugares, e que a governança em margens territoriais dos Estados-nações se desintegra. Tsing, por exemplo, considera essa maneira de imaginar margens fortemente influenciada 
por modelos espaciais, em que as margens se tornam definidas como locais onde a autoridade do Estado é menos confiável, e as diferenças entre os objetivos do Estado e sua realização local são maiores, enquanto o centro é imaginado como um lugar onde a autoridade do Estado é mais forte (TSING, 1993). Das e Poole (2004) destacaram que essa forma de olhar para o Estado e as margens assume que as metas e a autoridade do Estado são transparentes no centro, e que o próprio Estado não poderia ser investido na manutenção das margens como "espaços indisciplinados".

Em seu livro Capitalismo Gore, Sayak Valencia (2010, p. 5) afirma que, diante das forças transnacionais do norte global, alguns dos "subalternos-marginalizados" têm desenvolvido estratégias "ultraviolentas" a fim de obter capital. No entanto, ela contesta a ideia da zona fronteiriça EUA-México como abandonada, da margem sem governo, argumentando que na fronteira encontramos uma "dimensão do não-controle sistemático que é contraditório com o projeto neoliberal [ênfase minha]" (VALENCIA, 2010, p. 6). Aihwa Ong (2006), no entanto, afirma que essa contradição entre a falta de controle do Estado e o neoliberalismo é fictícia, argumentando que o capitalismo neoliberal produz continuamente essas áreas de negligência e marginalização, criando zonas de controle estatal diferencial.

Os dados sobre o trabalho sexual na fronteira México-EUA aqui apresentados mostram que apesar da distância geográfica do governo federal, o Estado não está ausente na fronteira, mas influi a vida diária das trabalhadoras sexuais de forma diferencial. No contexto do trabalho sexual na fronteira México-EUA, a governança do Estado cruza-se com a hierarquia racializada dos corpos sexualizados que opera na indústria do sexo em Tijuana, produzindo efeitos diferenciados. A hierarquia racializada operando na indústria do sexo em Tijuana classifica as mulheres mais brancas, mais finas, mais altas, e mais jovens que fizeram cirurgia de aumento dos seios no topo (HOFMANN, 2013). As trabalhadoras sexuais no pico da hierarquia racializada podem mais facilmente acessar melhores locais sexuais que permitem padrões de segurança mais elevados, ganhos maiores e melhores condições de trabalho. A capacidade de gerar maiores rendimentos lhes permite, além disso, cumprir com os testes de saúde obrigatórios e a validação contínua de seus cartões de saúde, permitindo assim maior proteção perante a corrupção policial. 
Sendo colocadas na parte inferior da hierarquia racializada, as mulheres indígenas encontram maiores dificuldades para fazer lucros altos e para entrar nos locais de classe alta que permitem condições de trabalho mais seguras. Trabalhadoras sexuais indígenas junto com mulheres mais velhas e mulheres cujos corpos são considerados menos atraentes dentro da hierarquia do mercado sexual (e.g. gordos) não conseguem ganhar o suficiente para sustentar o seu status jurídico como profissionais do sexo legítimas, portanto, são expostas a maiores riscos de corrupção policial. Obtendo menores ganhos também significa uma maior vulnerabilidade em termos da segurança espacial. Ganhos baixos forçam as trabalhadoras sexuais a morar na zona de prostituição, evitando assim os custos do transporte e se beneficiando dos aluguéis locais mais baratos. Porém, simultaneamente são expostas a atores empobrecidos da área envolvidos em atividades criminais e a condições habitacionais que não permitem o estabelecimento de segurança (nas cuarterías). Ao invés de um Estado distante ou ausente na zona fronteiriça, a governança do Estado presente em Tijuana cruza-se com a hierarquia racializada da indústria do sexo, produzindo uma série de efeitos diferenciados a respeito da posicionalidade racial, étnica e etária das mulheres.

\section{Conclusão}

A análise das experiências das trabalhadoras sexuais na zona fronteiriça de México-EUA traz alguns insights relevantes para aproximações teóricas das fronteiras. Como mostrei, muitas vezes as fronteiras são conceitualizadas como territórios distantes da influência do Estado e carentes de instituições governamentais, o que inevitavelmente resultaria na infração do Estado de Direito, na impunidade e no aumento da violência, tornando a zona fronteiriça num lugar perigoso e inseguro. A perspectiva das trabalhadoras sexuais em Tijuana ajuda a complexificar as imaginações binárias de Estado e margem em oposição entre si, e questionar a suposta incapacidade do Estado de ter o comando ao longo das margens territoriais da nação.

No caso das trabalhadoras sexuais, não é o Estado fraco ou fracassado que causa a exposição delas à violência e insegurança, mas as mesmas práticas de governança (dos dois Estados-nações presentes nessa 
fronteira) desempenham um papel significativo na vulnerabilização das mulheres. A insegurança e vulnerabilidade para a violência provém de uma coalescência da governança de saúde, da corrupção de agentes do Estado mexicano e do regime restritivo da imigração dos EUA. Das experiências das trabalhadoras sexuais na fronteira México-EUA apreendemos que mesmo que o perigo, a violência e a insegurança formam parte da vida na zona fronteiriça, os atores criminais que afetam suas vidas não são necessariamente aqueles comumente imaginados (i.e. traficantes de drogas e de seres humanos, atores não estatais); ao contrário, agentes corruptos do Estado mesmo formam parte da criação da insegurança que as trabalhadoras sexuais vivenciam junto com atores empobrecidos que tentam se beneficiar das trabalhadoras sexuais economicamente, muitos deles sendo vítimas do regime restritivo da imigração dos EUA.

Além disso, a perspectiva das trabalhadoras sexuais na fronteira nos ajuda entender que fronteiras podem ser consideradas como locais de atração e valorizadas como recursos que mobilizam e viabilizam migrações de lugares afastados. Expliquei como a indústria do sexo fronteiriça de Tijuana funciona como um ponto de atração para mulheres que já tinham vendido sexo em outras partes do México e para mulheres que decidiram experimentá-lo pela primeira vez. Na cidade fronteiriça de Tijuana, o trabalho sexual triunfa sobre o trabalho "quebra-costas" e mal pago nas maquilas, através de ganhos mais elevados, horários de trabalho flexíveis e menos horas de trabalho, liberando mais tempo para cuidar das crianças ou para atividades de educação contínua.

Apesar de múltiplos cruzamentos acontecendo diariamente na fronteira México-EUA, e inúmeras manifestações de travessias em produções culturais e na literatura acadêmica, que produzem percepções de dinamismo, flutuação, movimento, cruzamentos, mixagem e hibridismo, a fronteira México-EUA continua a ser uma barreira excludente para muitos cidadãos de ambos os lados que não conseguem usar a região fronteiriça como um espaço transnacional. Porém, os sujeitos temporariamente ou permanentemente excluídos da mobilidade transnacional, ou deslocam seus desejos em outras aspirações. As trabalhadoras sexuais se distanciaram do "troféu fronteira", da capacidade de atravessar, assim resistindo ativamente ao valor simbólico que ela tem e à degradação de suas vidas como não 
atravessadores, enfatizando que têm virado seus interesses para outros focos válidos.

Concluindo, sendo as geradoras principais de renda na zona norte, as trabalhadoras do sexo permanecem sujeitos vulneráveis diante das múltiplas inseguranças que definem esse espaço. A securitização da fronteira constitui um problema particular para as trabalhadoras do sexo, resultando em fluxos de pessoas deportadas sem recursos econômicos ou redes sociais no México que entram na zona norte, alguns deles, reclamando domínio do território da zona de prostituição e tentando de forma abusiva obter acesso a seus ganhos. Por outro lado, há atores estatais criminosos, particularmente a polícia, que tira proveito do regime de regulação de saúde de Tijuana, que coloca certas profissionais do sexo em desvantagem, as quais posteriormente se tornam vulneráveis à extorsão e abuso por parte da mesma polícia.

Porém, apesar do cenário de insegurança espacial, muitas trabalhadoras sexuais em Tijuana afirmaram que foi possível trabalhar no comércio sexual em uma área que é socialmente marginalizada e caracterizada pela dinâmica de diversas atividades ilegais, e ao mesmo tempo prosseguir com seu objetivo de avanço econômico. Tendo utilizado a indústria do sexo fronteiriça como recurso, muitas das mulheres com as quais falei voltaram para suas cidades e aldeias com capital economizado, fazendo possível assim aproveitar as vantagens e oportunidades associadas com o dinheiro no futuro.

\section{Referências}

ALFARACHE LORENZO, A. G. "Frauen, Migration und feminizide Gewalt in Mexiko." Em Dollares und Träume: Migration, Arbeit und Geschlecht in Mexiko im 21. Jahrhundert editado por Elisabeth TUIDER, Hanns WIENOLD, e Torsten BEWERNITZ. Münster: Westfälisches Dampfboot, 2009, 103-115.

ANGUIANO TELLEZ, M. E. e HERNÁNDEZ MADRID, M. (eds.). Migración internacional e identidades cambiantes. Zamora: El Colef. 2002. 
ANZALDÚA, G. Borderlands: the new mestiza: La frontera. San Francisco: Aunt Lute Books, 1987.

BAILEY, John, CHABAT, J. (eds.). Transnational Crime and Public Security: Challenges to Mexico and the United States. La Jolla: University of California at San Diego Center for U.S.-Mexican Studies Press, 2002.

BEJARANO, C. L.¿Qué Onda? Urban Youth Culture and Border Identity. Tucson: University of Arizona Press, 2007.

BURRIDGE, A. "Differential Criminalization under Operation Streamline: Challenges to Freedom of Movement and Humanitarian Aid Provision in the Mexico-US Borderlands" Refuge: Canada's Journal on Refugees 26 (2): 2009, 78-91.

CACHO, L. Los demonios del Edén: El poder que protege a la pornografía infantil. México, D.F.: Grijalbo, 2006.

CASTILlO, D. A., RANGEL GÓMEZ, M.G., ROSAS, A. "Violencia y Trabajadores Sexuales Travestis y Transgéneros en Tijuana" Debate feminista. 33, 2006. p. 7-20.

CASTILlO, D. A., RANGEL GÓMEZ, M. G., DELGADO, B. "Border Lives: Prostitute Women in Tijuana." Signs: Journal of Women in Culture and Society 24(2), 1999. p. 387-422.

CHÁVEZ, S. The Making of a Border Labor Migration System: Government Policies, Labor Markets, and Social Networks in Tijuana. Tese de doutorado, Cornell University, 2007.

CISNEROS, J. D. The Border Crossed Us: Rhetorics of Borders, Citizenship, and Latina/o Identity. Tuscaloosa: The University of Alabama Press, 2014.

CUEVA LUNA, T. E. e Belem Iliana VAZQUEZ GALAN. Fenomenos sociales $y$ urbanos transfronterizos entre Mexico y Estados Unidos. Tijuana: El Colef, 2009.

CURTIS, J., D. ARREOLA, D. Zonas de Tolerancia on the Northern Mexican Border. Geographical Review 81(3), 1991. p. 333-346. 
DAS, V., POOLE, D. "State and Its Margins: Comparative Ethnographies." In: Anthropology in the Margins of the

State. Santa Fe: School of American Research Press; Oxford: James Currey, 2004.

DOMINGO, P. Rule of Law, Citizenship and Access to Justice in Mexico. Mexican Studies/Estudios Mexicanos, 15(1), 1999. p. 151191.

FORTE, M. C. Indigenous Cosmopolitans: Transnational and Transcultural Indigeneity in the Twenty-First Century. New York: Peter Lang Publishing, 2010.

HERZOG, L. A. Global Tijuana: The Seven Ecologies of the Border. In: DEAR, M., LECLERC, G. Post Border City: Cultural Spaces of Bajalta California. London: Routledge, 2003. p.119 - 142.

HIRSCH, J. S. A. Courtship After Marriage: Sexuality and Love in Mexican Transnational Families. Berkeley: University of California Press, 2003.

HOFMANN, S. Lebensgeschichten von Sexarbeiterinnen in Mexiko-City: Eine ethnologische Untersuchung zu Gewalterfahrungen im Geschlechterverhältnis. Dissertação de mestrado, Universidade Libre de Berlin, 2005.

HOFMANN, S. Aesthetic Labour, Racialization and Aging in Tijuana's Cosmopolitan Sex Industry." In: JAFAR, A., MASI DE CASANOVA, E. Global Beauty, Local Bodies. New York: Palgrave Macmillan, 2013. p. 23-50.

HUBBARD, P., SANDERS, T. Making Space for Sex Work: Female Street Prostitution and the Production of Urban Space. International Journal of Urban and Regional Research 27(1), 2003. p. 75-89.

HUMAN RIGHTS WATCH (HRW). Systemic Injustice: Torture, "Disappearance," and Extrajudicial Execution in Mexico. New York: HRW, 1999. 
KARWOSKI GIDEONSE, T. Hybridity as Cultural Capital on the US/Mexican Border. Dissertação de mestrado, Universidade de California/ San Diego, 2007.

LATTANZI SHUTIKA, D. Beyond the Borderlands: Migration and Belonging in the United States and Mexico. Berkeley: University of California Press, 2011.

LEFEBVRE, H. Critique of Everyday Life. London: Verso, 1991.

MARTÍNEZ, O. J. Border People: Life and Society in the U.S.Mexico Borderlands. Tucson: University of Arizona Press, 1994.

MURIA TUÑÓN, M. Enforcing Boundaries: Globalization, State Power and the Geography of Cross-Border Consumption in Tijuana, Mexico. San Diego: University of California, 2010.

NEVINS, J. Operation Gatekeeper: The Rise of the "Illegal Alien" and the Making of the U.S.-Mexico Boundary. New York: Routledge, 2002.

ONG, A. Neoliberalism as Exception: Mutations in Citizenship and Sovereignty. Durham: Duke University Press, 2006.

PRICE, J. A. Tijuana: Urbanization in a Border Culture. London: University of Notre Dame Press, 1973.

REAGAN, L. J. Crossing the Border for Abortions: California Activists, Mexican Clinics, and the Creation of a Feminist Health Agency in the 1960s. Feminist Studies. 26(2), 2000. p. 323-348.

RIVERA-SALGADO, G. Migration and Political Activism: Mexican Transnational Indigenous Communities in a Comparative Perspective. Tese de Doutorado, Universidade de California, 1999.

SALZINGER, L. Genders in Production: Making Workers in Mexico's Global Factories. Berkeley: University of California Press, 2003.

SCHAEFFER-GABRIEL, F. Cyber-brides Between the United States and Mexico: Transnational Imaginaries, Migration, and the 
Intimate Economy of Marriage. Tese de Doutorado, Universidade de Minnesota 2003.

SEGURA, D. A. e ZAVELLA, P. (eds.). Women and Migration in the U.S.-Mexico Borderlands: A Reader. Durham: Duke University Press, 2007.

SMITH, M. P., BAKKER, M. Citizenship Across Borders: The Political Transnationalism of El Migrante. Ithaca: Cornell University Press, 2008.

SMITH, N. Spaces of Vulnerability: The Space of Flows and the Politics of Scale. Critique of Anthropology .16(1): 63-77, 1996.

STAUDT, K. A. Violence and Activism at the Border: Gender, Fear, and Everyday Life in Ciudad Juárez. Austin: University of Texas Press, 2008.

STEPHEN, L. Transborder Lives: Indigenous Oaxacans in Mexico, California, and Oregon. Durham: Duke University Press, 2007.

TSING, A. L. In the Realm of the Diamond Queen: Marginality in an Out-of-the-way Place. Princeton: Princeton University Press, 1993.

VALENCIA, S. Capitalismo Gore. Madrid: Melusina, 2010.

VALENZUELA ARCE, J. M. A la brava ese: cholos, punks, chavos banda. Tijuana: El Colegio de la Frontera Norte, 1988.

VALERIO-JIMÉNEZ, O. S. River of Hope: Forging Identity and Nation in the Rio Grande Borderlands. Durham: Duke University Press, 2013.

VELASCO ORTIZ, L. (coord). Migración, fronteras e identidades étnicas transnacionales. Tijuana, B.C.: Colegio de la Frontera Norte; México, D.F.: Miguel Ángel Porrúa 2008.

VELASCO ORTIZ, M. L. Mixtec Transnational Identity. Tucson: University of Arizona Press, 2005.

VILA, P. Border Identifications. Ciudad Juárez: El Colegio de Chihuahua/ Universidad Autónoma de Ciudad Juárez, 2007. 
WILSON, T. D. Women's Migration Networks in Mexico and Beyond. Albuquerque: University of New Mexico Press, 2009.

WRIGHT, M. W. Disposable Women and Other Myths of Global Capitalism. London: Routledge, 2006.

ZEPEDA LECUONA, G. Inefficiency at the Service of Impunity: Criminal Justice Organizations in Mexico. In: BAILEY, J. e CHABAT, J. Transnational Crime and Public Security. San Diego: Lynne Rienner, 2002. p. 71-107. 